\title{
The influence of contact stress on the wear of cross-linked polyethylene
}

\author{
Göksu Kandemir, Simon Smith and Thomas J Joyce
}

School of Engineering, Newcastle University, Newcastle upon Tyne

\section{Corresponding author:}

Göksu Kandemir, Newcastle University, Newcastle Upon Tyne, NE1 7RU, UK

School of Engineering

E-mail:G.Kandemir2@ncl.ac.uk

\begin{abstract}
Generation of wear debris and wear particle-induced osteolysis are the main limitations of metal-on-polyethylene artificial joints. Cross-linked polyethylene has been recently used, particularly in hip replacements, as an alternative material to conventional ultrahigh molecular weight polyethylene due to its superior wear resistance. This study focused on the wear behaviour of cross-linked polyethylene under different contact stresses in order to make interpretations of its long-term in-vivo performance. A 50-station SuperCTPOD (pin-on-disc) machine was used to investigate the influence of contact stress on the wear of cross-linked polyethylene pins which were articulated against cobalt chromium discs. It was found that the wear rate of cross-linked polyethylene was lower at higher contact stresses.
\end{abstract}

\section{Keywords}

Wear, contact stress, in-vitro testing, cross-linked polyethylene, artificial hip implants

\section{Introduction}

Total hip replacement (THR) is the most successful surgical procedure that is used to treat diseases such as osteoarthritis ${ }^{1,2}$. Approximately 1 million patients have hip replacements every year and this number is likely to rise due to an increase in demand from relatively younger patients ${ }^{3-6}$. The most commonly used bearing combination in artificial hips is metal-on-polyethylene (MoP). A typical artificial hip’s main components include an ultrahigh molecular weight polyethylene (UHMWPE) acetabular liner or cup, and a cobalt chromium (CoCr) metallic femoral head. Clinical studies show that MoP hips are quite 
successful in the short and medium terms ${ }^{7-11}$. However, in the long term, wear of the polyethylene component can result in wear particle-induced osteolysis and, secondary to osteolysis, aseptic loosening may also occur ${ }^{12}$. Greater wear is therefore linked with reduced longevity of the artificial hip ${ }^{3,9,10,13-15}$.

Since wear of the UHMWPE cup/liner is the main reason for the failure and revision of MoP hips ${ }^{6}$, the need for more wear resistant materials has arisen. Cross-linked polyethylene (XLPE) is one of the alternatives that has been used in hip arthroplasty for the past 10 to 20 years and clinical studies show that cross-linking has improved the wear resistance of the material and XLPE has a superior wear resistance compared to UHMWPE $3,8,16-21$.

The superior wear performance of XLPE over UHMWPE has also been observed in laboratory studies ${ }^{4}$. While this is reassuring for an application as important as in the human body, it is imperative to ensure that all appropriate testing has been undertaken. One area that does not appear to have been considered, is the wear behaviour of XLPE under varying contact stresses. Consequently the motivation of this study was to undertake the first, to the authors' best knowledge, tribological study of the wear of XLPE under different contact stresses relevant to those in a THR.

According to some clinical studies, the average contact stresses that act on the natural hip can range from 0.1 to $5.6 \mathrm{MPa}$, with a maximum peak contact stress of $10 \mathrm{MPa}{ }^{22}$. In addition to this, using a finite element study, Henak at al. ${ }^{23}$ found an average contact stress of $5.32 \pm 2.32 \mathrm{MPa}$ acting on the hip joint. Thus, the components that make up artificial hips need to withstand these stresses, especially the polymeric acetabular cup/liner in order to minimise the incidence of osteolysis and aseptic loosening.

Some in-vitro wear studies of UHMWPE showed that, as the contact stress increased, the wear volume decreased ${ }^{8,24-27}$. These studies are summarised in table 1 . 
Table 1. In vitro studies that investigated the effect of contact stress on the wear of UHMWPE.

\begin{tabular}{|c|c|c|c|}
\hline Author(s) & $\begin{array}{l}\text { Contact stress } \\
\text { range } \\
(\mathrm{MPa})\end{array}$ & $\begin{array}{l}\text { Calculated wear } \\
\text { factor range } \\
\text { (x 10-6 } \frac{\mathbf{m m}^{3}}{\mathbf{N m}} \text { ) }\end{array}$ & $\begin{array}{l}\text { Wear factor }(\mathrm{k}) \text {-contact stress } \\
(\sigma) \text { relation }\end{array}$ \\
\hline Barbour et al. ${ }^{8}$ & 28.3-3.4 & $0.01-0.02$ & $k=e^{-0.035 * \sigma}$ \\
\hline Wang et al. ${ }^{27}$ & $24.0-5.0$ & $1.00-2.79$ & $k=7.99 * 10^{-6} * \sigma^{-0.65}$ \\
\hline $\begin{array}{l}\text { Vassiliou and } \\
\text { Unsworth } 24\end{array}$ & $12.73-0.56$ & $0.24-3.26$ & $k=2.00 * 10^{-6} * \sigma^{-0.84}$ \\
\hline Saikko ${ }^{26}$ & 20.0-0.1 & $0.09-10.65$ & $\begin{array}{r}k=2.70 * 10^{-6} *\left(\frac{\sigma}{\sigma_{\text {ref }}}\right)^{-0.57}, \\
\frac{\sigma}{\sigma_{\text {ref }}} \leq 2.53 \\
k=6.00 * 10^{-6} *\left(\frac{\sigma}{\frac{\sigma}{\sigma_{r e f}}}\right)^{-1.44} \\
\frac{\sigma}{\sigma_{\text {ref }}}>2.53\end{array}$ \\
\hline Saikko ${ }^{25}$ & $5.85-0.65$ & $1.06-7.91$ & $\begin{array}{rl}k=6.52 * 10^{-8} & * \frac{73.5}{\sigma} \\
& +2.35 * 10^{-7}\end{array}$ \\
\hline
\end{tabular}

$\mathrm{k}$ : wear factor $\left(\frac{\mathrm{mm}^{3}}{\mathrm{Nm}}\right) \sigma$ : nominal contact stress (MPa), $\sigma_{r e f}$ : reference nominal contact pressure (1.10 MPa). (In Saikko ${ }^{25}$ 's study the effect of contact area on the wear of UHMWPE was investigated and the relation between contact area and the wear factor was provided in terms of contact area. For consistency, the contact area term has been changed to $\frac{\operatorname{Load}(N)}{\text { Contact Stress (MPa) }}$ in table 1).

Barbour et al. ${ }^{8}$ investigated the effect of contact stress on the wear of UHMWPE test pins with contact stresses ranging from 3.4 to 28.3 MPa. It was found that the wear factor tended to decrease with increasing contact stress. However, pins were formed with truncated cones as the wear faces, meaning that the contact area might increase as wear occurs. In addition, the wear test machine applied reciprocation-only motion which has been shown to be inappropriate for wear testing orthopaedic biopolymers ${ }^{28}$. This likely explains the low wear factors compared with other studies which investigated the influence of contact stress. Wang et al. ${ }^{27}$ investigated the effect of contact stress on wear of UHMWPE using a hip simulator. They showed that, for a given load, wear factor decreased with increasing 
contact stress. Vassiliou and Unsworth ${ }^{24}$ applied multi-directional motion to their UHMWPE test pins. To obtain higher contact stresses, pins were drilled out to form an annulus. Again, the wear was found to decrease with increasing contact stress. Saikko ${ }^{26}$ used a 100-station pin-on-disc machine applying multi-directional motion and found that wear factor values decreased with increasing contact stress. A contact stress range of 0.1 to $20 \mathrm{MPa}$ was tested. A critical contact stress of $2.53 \mathrm{MPa}$ was found, in that the wear behaviour was found to be different below and above this value; so that two equations were used to characterise the contact stress and wear factor relation, see table 1. Most recently, Saikko ${ }^{25}$ tested 16 UHMWPE pins that were articulated against CoCr discs under contact stresses of 0.65, 1.16, 2.31 and 5.85 MPa. Again, wear factor was found to decrease with increasing contact stress.

In the light of these findings for UHMWPE, this study aimed to determine whether this same result of wear decreasing with increased stress, applied to XLPE.

Equation (1) was used to calculate the wear factor $\left(\mathrm{k}, \frac{\mathrm{mm}^{3}}{\mathrm{Nm}}\right)$.

$$
k=\frac{V}{L D}
$$

where $\mathrm{V}$ is the volume loss $\left(\mathrm{mm}^{3}\right)$, L is the load applied $(\mathrm{N})$ and $\mathrm{D}$ is the total sliding distance (m) of the pins. As shown in equation 1, wear factor depends on the applied load and the sliding distance. Wear should therefore be independent of contact stress.

\section{Materials and Methods}

A 50-station circularly translating pin-on-disc machine (SuperCTPOD), designed by Saikko ${ }^{29}$, was used to investigate the effect of contact stress on the wear of XLPE. The multi-station SuperCTPOD enables simultaneous testing of pins with different characteristics under the same testing conditions. It consists of five main modules, namely the loading module, pin carrier module, the motion module, the test bath and the control panel (Figure 1). 


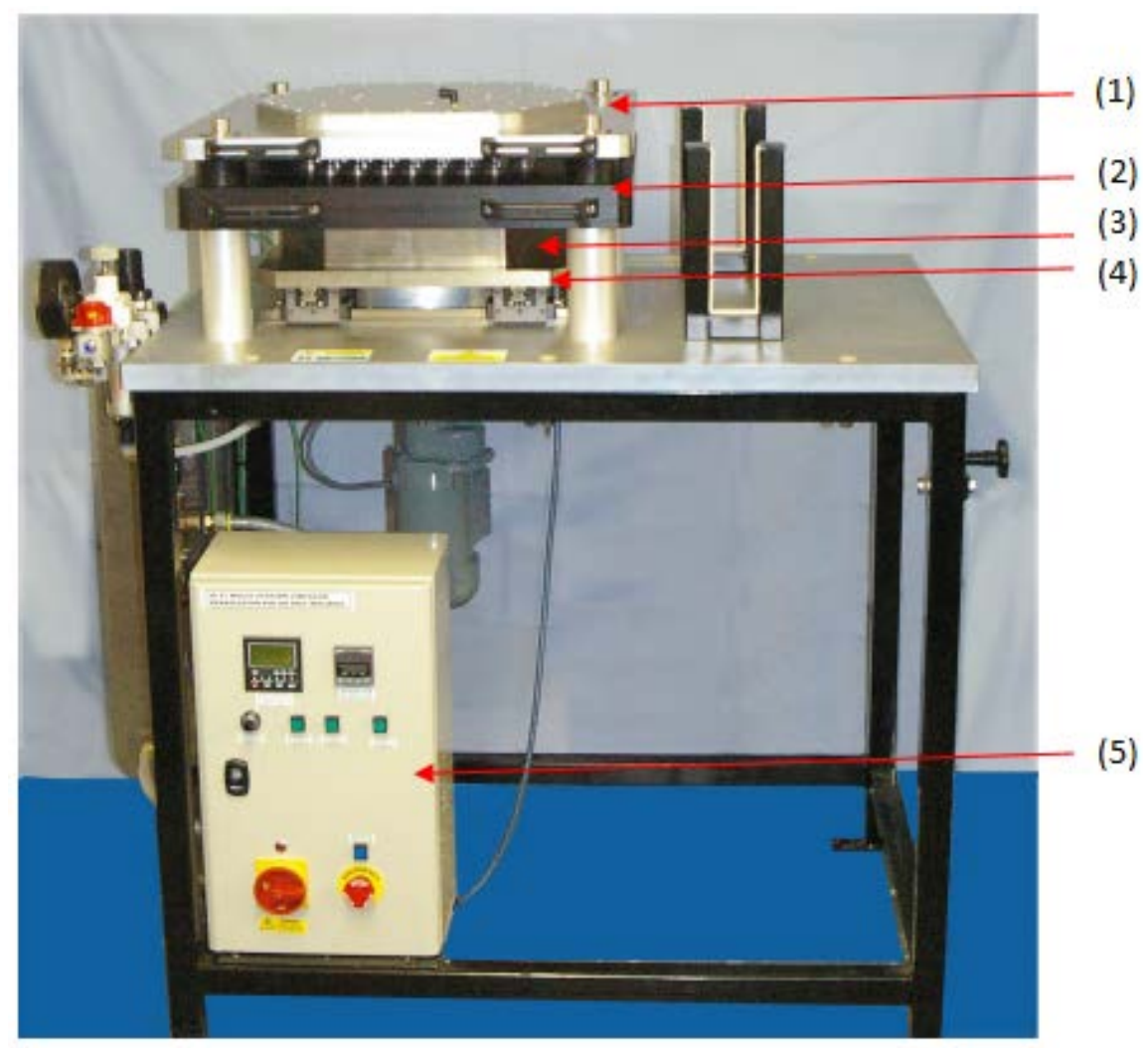

Figure 1. Multi-station SuperCTPOD that consists of a loading module (1), pin carrier module (2), test bath (3), motion module (4) and control unit (5).

Fifty individual pneumatic cylinders within the loading module apply an equal static load to each of the 50 test pins, with the air pressure supplied from a compressor. The loading module mounts on top of the pin carrier module. The pin carrier module carries the test pins, each held in a polyacetal sleeve. The motion module is a platform that is actuated by a double scotch yoke mechanism driven by an AC geared motor. Above the motion module is the test bath, which is mounted on an x-y slide assembly. The frequency and the wear track path of the pins can be adjusted to achieve the desired motion. The orthogonal axis can be set to either reciprocating motion, elliptical orbital motion or circular orbital motion. The test bath provides the location for the test pin-disc assemblies. The test load, circulating fluid temperature and flow rate, number of cycles and orbiting frequency are all controlled from the control panel. O-rings are fitted to the discs and the PVC tubes are pressed on the discs to form the disc assemblies, see figure 2. 


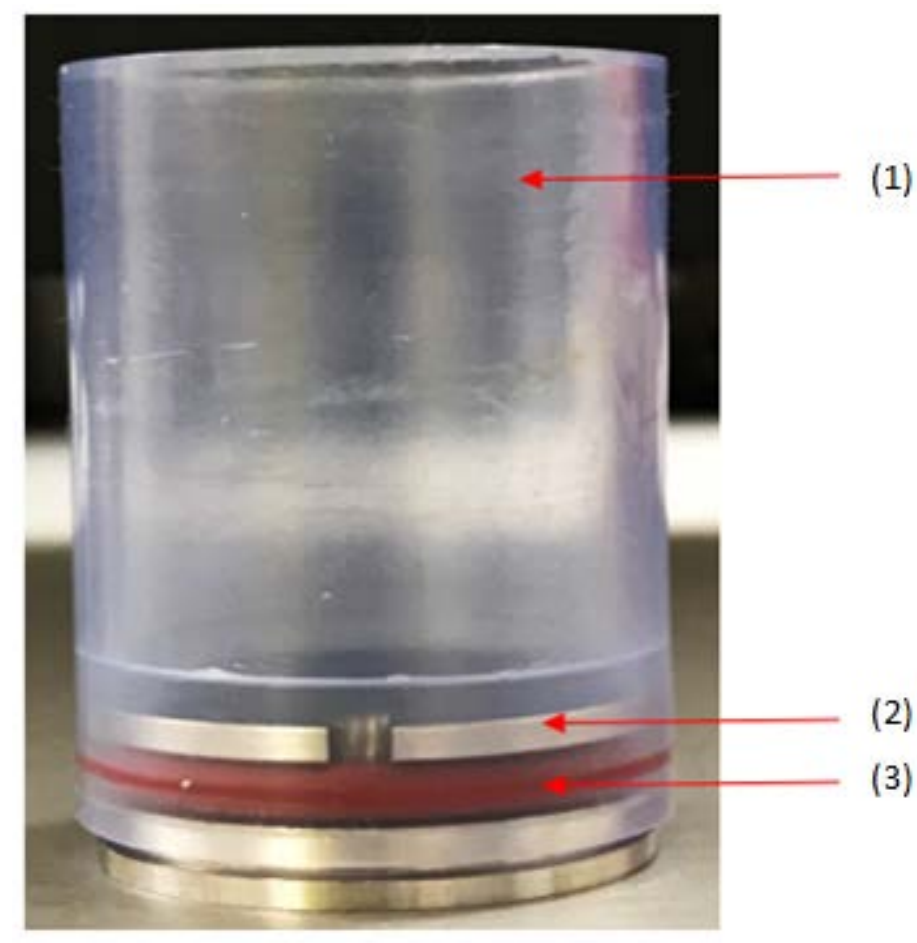

Figure 2. Disc assembly; (1) PVC tube, (2) CoCr disc and (3) O-ring.

During testing, the assemblies were all fitted in the test bath module. Every pin was articulated against the same, corresponding disc throughout the experiment. The temperature inside the test bath was measured with a thermocouple. The lubricant temperature was maintained approximately at $22{ }^{\circ} \mathrm{C}$. The test rig ran at a frequency of 1 $\mathrm{Hz}$. During the test, the major axis was set to an amplitude of $6 \mathrm{~mm}$ and the minor axis (the orthogonal axis) was set to an amplitude of $5 \mathrm{~mm}$ to achieve an elliptical wear track path of 12 x $10 \mathrm{~mm}$. This wear path resulted in $34.62 \mathrm{~mm}$ sliding distance per cycle. Harsha and Joyce ${ }^{4}$ used the same elliptical wear track and corresponding sliding distance per cycle to test UHMWPE and XLPE test pins so that their results were available to compare with the results of this study.

The base XLPE material, from which pins were machined, was purchased from Orthoplastics (Bacup, UK) and the material properties provided by the supplier are summarised in table 2 . 
Table 2. Material properties of the XLPE test pins.

\begin{tabular}{|l|l|}
\hline Dosage received & $76.7 \mathrm{kGy}$ \\
\hline Density & $928.2 \mathrm{~kg} / \mathrm{m} 3$ \\
\hline Tensile stress at yield at $23^{\circ} \mathrm{C}$ & $20.6 \mathrm{MPa}$ \\
\hline Ultimate tensile stress at yield at $23^{\circ} \mathrm{C}$ & $47 \mathrm{MPa}$ \\
\hline Elongation at break at $23^{\circ} \mathrm{C}$ & $267(\%)$ \\
\hline
\end{tabular}

Wear data calculated for the same contact stresses (range:1.46 - 6.11 MPa) for UHMWPE 24,25 was used to conduct a statistical analysis to give sample size estimation ${ }^{30}$.The number of pins required for this study was estimated with equation (2).

$$
\text { Standardised difference }=\frac{\text { difference between the means }}{\text { population standard deviation }}
$$

These resulted in the need for a sample size of 9 for a power level of 0.80 . As the SuperCTPOD has a capability of testing 50 pins, a sample size of 10 was chosen, as this met the power size calculation and gave a spare pin in case of an unforeseen issue with a test pin. The pins tested were $9 \mathrm{~mm}$ in outer diameter and $12 \mathrm{~mm}$ in height and they were divided into 5 groups.

Apart from group 1, the pins from each group were drilled with different diameter holes to have different contact areas and consequently different contact stresses (figure 3). 


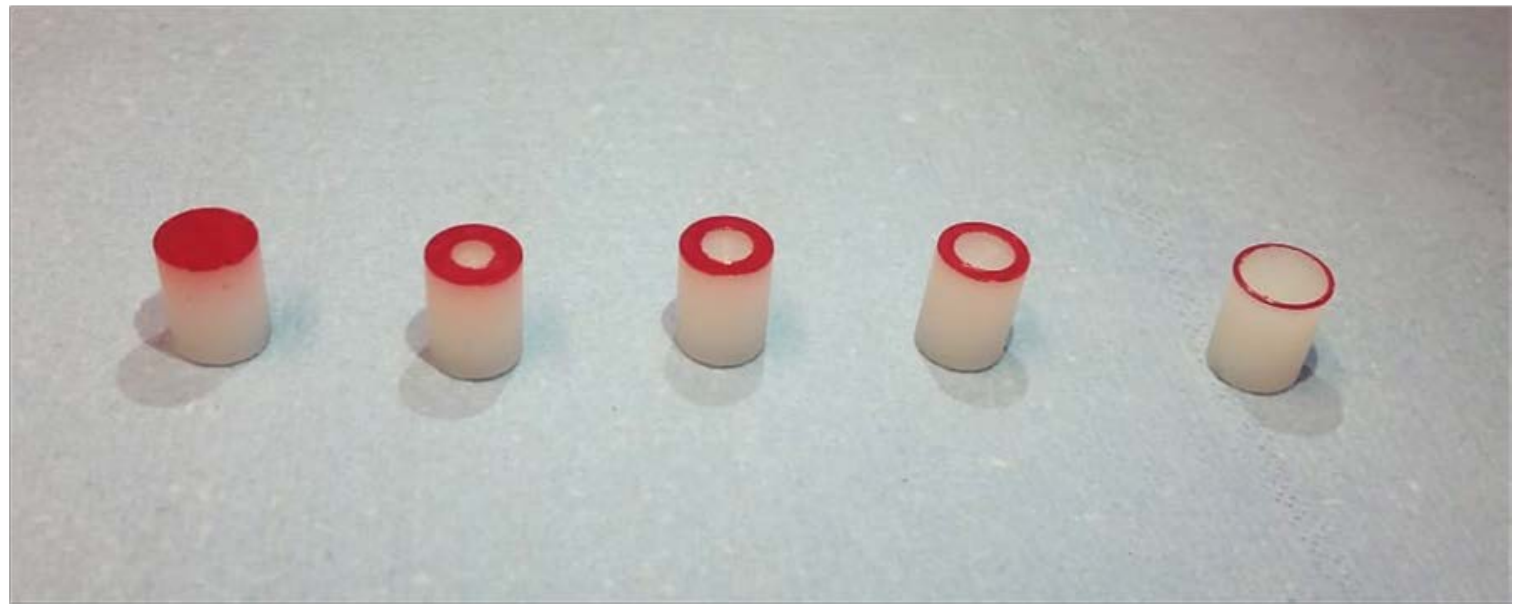

Figure 3. XLPE test pins. From left to right, pin from group 1 (1.11 MPa), group 2 (1.38 $\mathrm{MPa})$, group $3(1.61 \mathrm{MPa})$, group $4(2.00 \mathrm{MPa})$ and group 5 (5.30 MPa). The articulating surfaces were painted in red for better contrast.

The inner and outer diameter values of the pins before starting the experiment, and the corresponding contact areas and contact stresses are provided in table 3. A load of $70.7 \mathrm{~N}$ was applied to the pins. Each test pin articulated against CoCr discs, which were all of diameter of $28 \mathrm{~mm}$, a thickness of $10 \mathrm{~mm}$, and polished to less than $0.050 \mu \mathrm{m}$ Ra.

Table 3. The inner and outer diameters of the pins of each group and their corresponding contact area and contact stress values.

\begin{tabular}{|l|l|l|l|l|l|}
\hline $\begin{array}{l}\text { Group } \\
\text { number }\end{array}$ & $\begin{array}{l}\text { Number of } \\
\text { pins in the } \\
\text { group }\end{array}$ & $\begin{array}{l}\text { Outer } \\
\text { Diameter } \\
(\mathrm{mm})\end{array}$ & $\begin{array}{l}\text { Inner } \\
\text { Diameter } \\
(\mathrm{mm})\end{array}$ & $\begin{array}{l}\text { Contact } \\
\text { Area } \\
\left(\mathrm{mm}^{2}\right)\end{array}$ & $\begin{array}{l}\text { Contact } \\
\text { Stress } \\
(\mathrm{MPa})\end{array}$ \\
\hline 1 & 10 & 9.00 & - & 63.62 & 1.11 \\
\hline 2 & 10 & 9.00 & 4.00 & 51.05 & 1.38 \\
\hline 3 & 10 & 9.00 & 5.00 & 43.98 & 1.61 \\
\hline 4 & 10 & 9.00 & 6.00 & 35.34 & 2.00 \\
\hline 5 & 10 & 9.00 & 8.00 & 13.35 & 5.30 \\
\hline
\end{tabular}


The contact stresses given in table 3 are clinically relevant based on the data in the literature for the contact stresses that act on the natural human hip ${ }^{22}$. The contact stresses that were tested in this study ranged from 1.11 to $5.30 \mathrm{MPa}$. Group 1 pins were tested at a contact stress of 1.11 MPa which was the contact stress used by other studies ${ }^{3-6}$. According to the in-vitro studies conducted by Saikko the contact stresses should not exceed 2 MPa for a pin-on-disc test because above this value the UHMWPE wear data is inconsistent with clinical data ${ }^{25}$ 26. However, a higher contact stress (Group 5: 5.30 MPa) was selected to allow a fuller investigation, to match the value suggested by Henek et al. ${ }^{23}$ and allow comparison with other studies ${ }^{25,26}$.

The pin carrier module with the pins and the test bath holding the disc assemblies filled with lubricant are shown in figure 4.

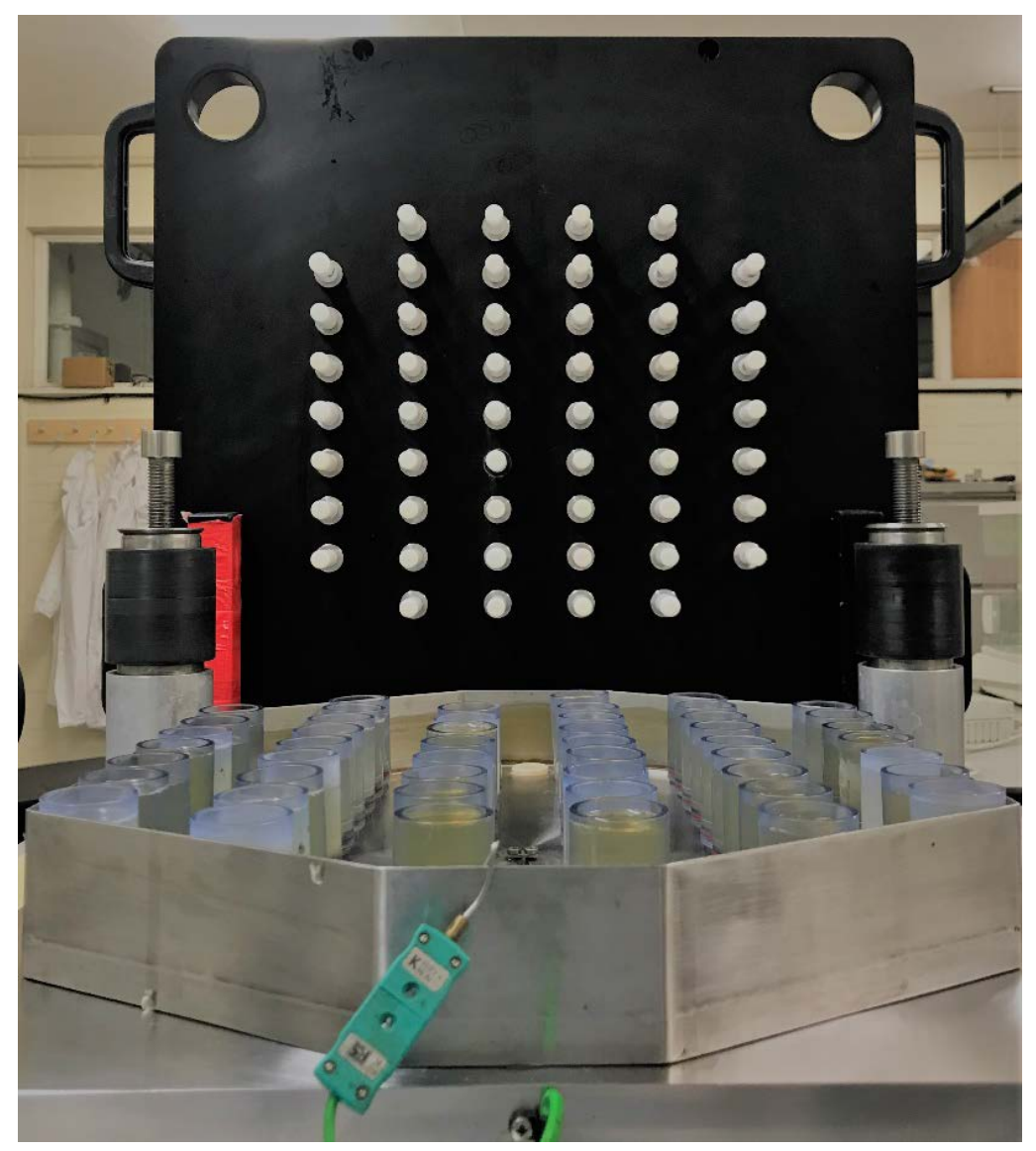

Figure 4. View of the pin carrier module holding the test pins inside polyacetal sleves (above) and the test bath located on the motion module with the disc assemblies (below). 
Newborn calf serum (Thermo Fisher Scientific, USA) was used as the basis of the lubricant, which was diluted with distilled water in a ratio of $1: 2$ to result in a protein content of $22 \mathrm{~g} / \mathrm{L}$. In a study conducted by Saikko, it was found that the lubricant protein concentration should not be lower than $20 \mathrm{~g} / \mathrm{L}$ as this led to non-typical clinical results ${ }^{31}$. The optimum lubricant protein concentration was found to be $22 \mathrm{~g} / \mathrm{L}$ for the wear testing of artificial joints ${ }^{31}$ and this ratio was used in other in-vitro tests ${ }^{4,29}$ as well.

Before starting the experiment, all the pins and discs were cleaned and weighed, numbered and their surface roughness values ( $\mathrm{Ra}$ ) were measured. The experiment was stopped every 500,000 cycles to replace the lubricant. The weight loss and the surface roughness measurements for pins and discs were performed every time the experiment was stopped. In total, six measurements were done for both weight loss and surface roughness. The weight measurements were undertaken using a Denver TB-215D balance which has a precision of $10 \mu \mathrm{g}$. The surface roughness measurements of the discs and the pins were done with a ZYGO New View 5000 non-contacting profilometer which has a sensitivity of $0.001 \mu \mathrm{m}, \mathrm{Ra}^{32}$.

When the test was stopped at regular intervals, the pins, the discs and all other equipment used in the experiment were all placed in containers containing diluted disinfectant (Virkon). After 5 minutes, every component was rinsed under tap water and allowed to dry in air for 5 minutes. The pins and disc were washed with Isopropanol alcohol, the weight and surface roughness measurements were done, and if needed, components were renumbered prior to a new cycle of testing because Isopropanol alcohol may erase the number written on the pins and the discs.

In every pin group, an additional pin was used as a control pin to track any change in weight due to lubricant uptake. The test ran for 2.5 million cycles (corresponding to approximately $87 \mathrm{~km}$ sliding distance).

\section{Results}

After 2.5 million cycles the mean wear rates of the test pin groups were calculated as 1.05, $0.90,0.77,0.47$ and $0.28 \mathrm{mg}$ per million cycles for contact pressures of $1.11,1.38,1.61$, 
2.00 and 5.30 MPa respectively. The results are summarized in table 4 along with corresponding wear factors.

Control pin values were taken into account when calculating the true weight change of the test pins and thus the true volume loss. At the end of the experiment, the mean weight changes from the control pins were found to be $0.15,0.18,0.15,0.16$ and $0.10 \mathrm{mg}$ respectively.

Table 4. Summary of the wear rates and wear factors of the pin groups.

\begin{tabular}{|l|l|l|}
\hline & Wear Rates $\left(\frac{\mathbf{m g}}{\mathbf{M c}}\right) \pm \mathrm{SD}$ & Wear factor $\left(\frac{\mathbf{m m}^{3}}{\mathbf{N m}}\right) \times 10^{-6} \pm \mathrm{SD}$ \\
\hline Group 1 (1.11 MPa) & $1.05 \pm 0.35$ & $0.46 \pm 0.16$ \\
\hline Group 2 (1.38 MPa) & $0.90 \pm 0.28$ & $0.39 \pm 0.12$ \\
\hline Group 3 (1.61 MPa) & $0.77 \pm 0.24$ & $0.34 \pm 0.11$ \\
\hline Group 4 (2.00 MPa) & $0.47 \pm 0.22$ & $0.21 \pm 0.09$ \\
\hline Group 5 (5.30 MPa) & $0.28 \pm 0.12$ & $0.12 \pm 0.05$ \\
\hline
\end{tabular}

Mc: million cycles, SD: Standard Deviation 


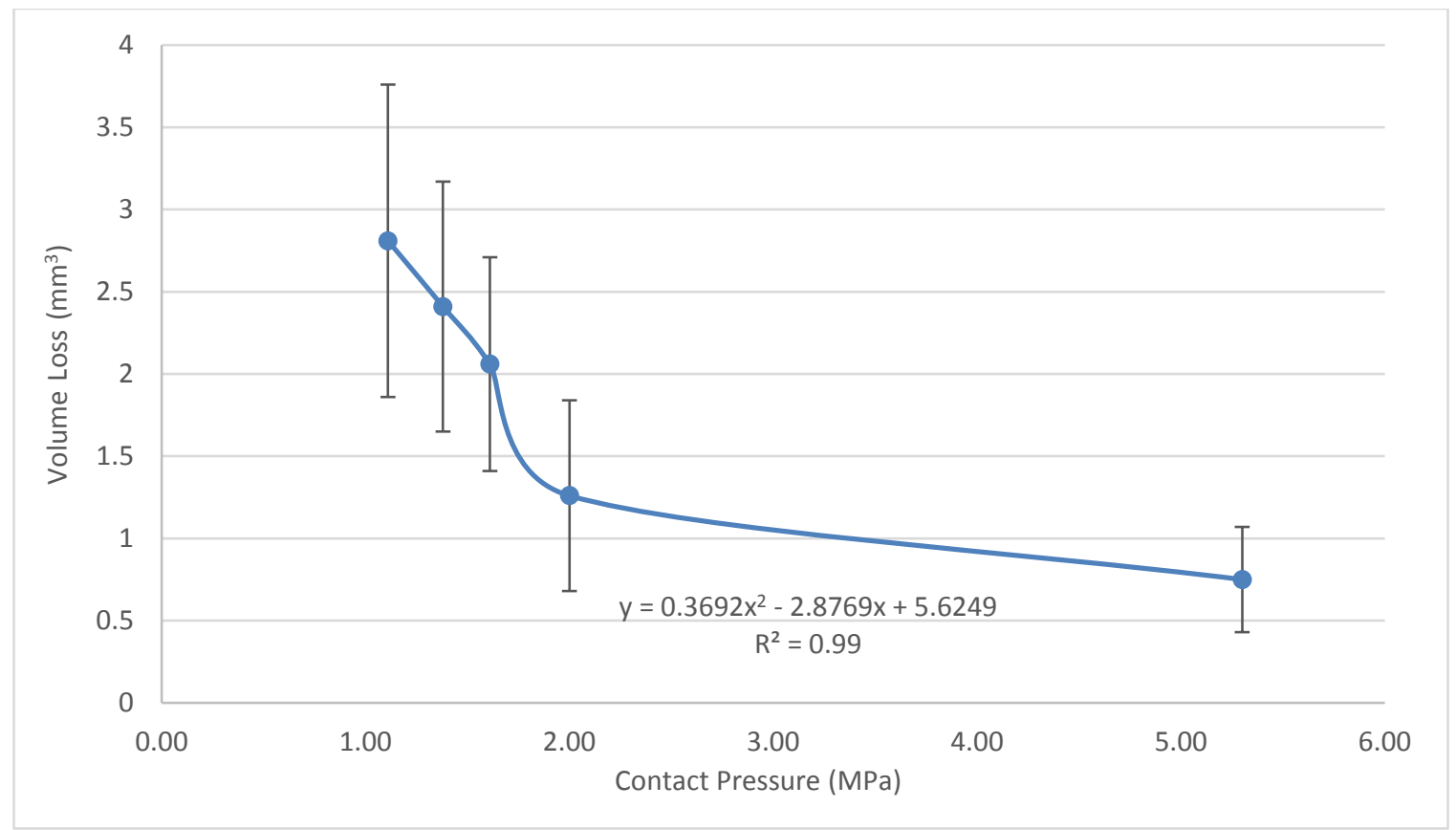

Figure 5. Volume loss from the pin groups at the end of the experiment.

Volume loss of the XLPE pins decreased as the contact stress increased (figure 5) and can be represented with a quadratic polynomial function, $\mathrm{V}=0.37 * \sigma^{2}-2.88 * \sigma+5.62$. Wear factors of the pins at the end of the experiment were calculated using equation 1 and the relation between wear factor and contact stress was found to be a power function; $k=0.40 * 10^{-6} * \sigma^{-0.88}$. 


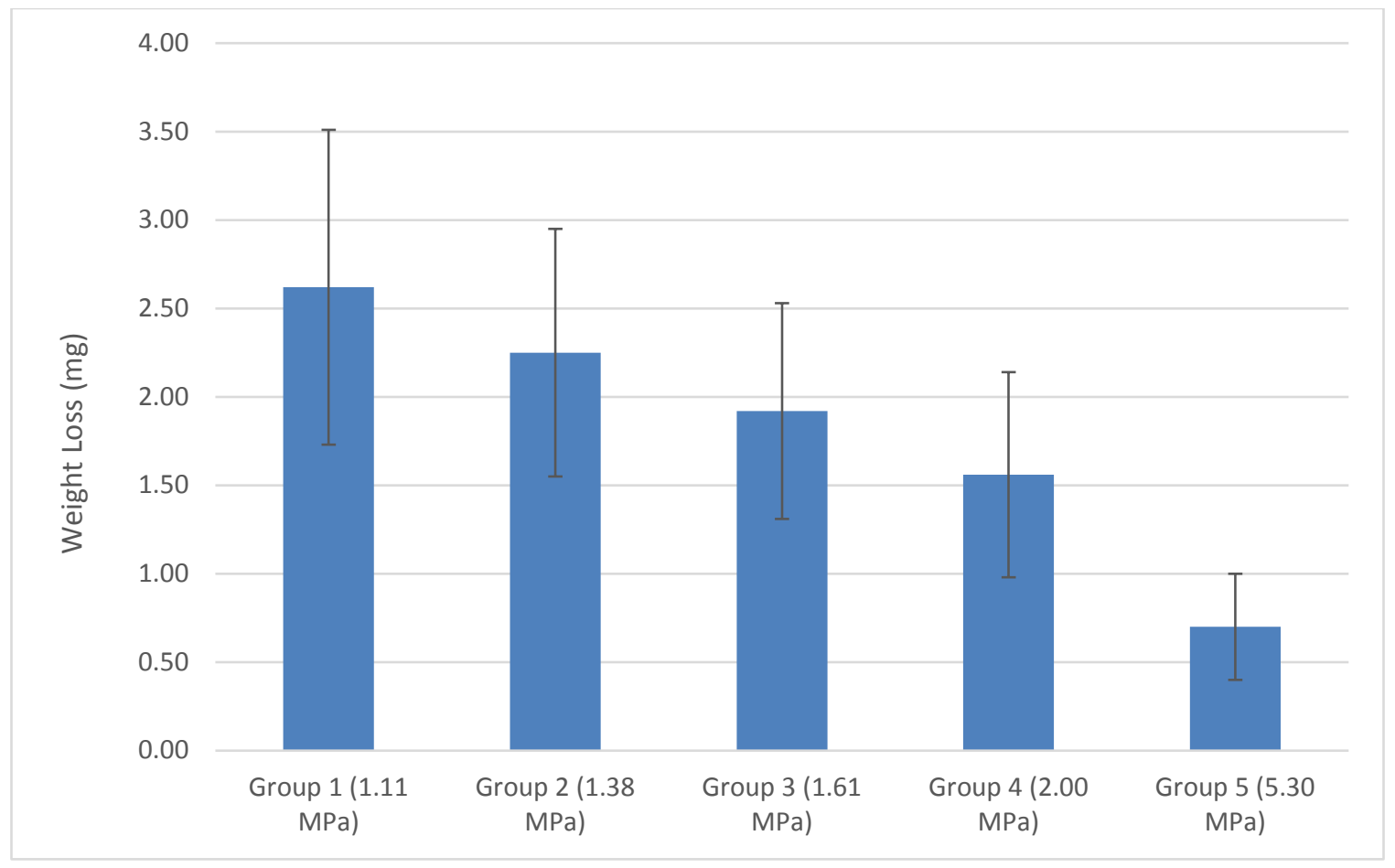

Figure 6. Average weight loss from the pin groups after 2.5 Million Cycles.

The total weight loss of the pin groups after 2.5 million cycles is given in figure 6 . The weight loss from each group at the end of the experiment was found to be $2.62 \pm 0.89,2.25$ $\pm 0.70,1.92 \pm 0.61,1.56 \pm 0.58,0.70 \pm 0.30 \mathrm{mg}$ for contact stresses of $1.11,1.38,1.61$, 2.00, and 5.30 MPa respectively.

Before starting the experiment, the surface roughness values of the test pins were $0.51 \pm$ $0.07,0.45 \pm 0.06,0.42 \pm 0.09,0.48 \pm 0.07$ and $1.48 \pm 0.28 \mu \mathrm{m}$ respectively. At the end of the experiment, the surface roughness values $(\mathrm{Ra})$ of all the pins had decreased compared to their initial values. After $2.5 \mathrm{Mc}$ the surface roughness values of the pin groups reduced to $0.23 \pm 0.12,0.24 \pm 0.08,0.30 \pm 0.11,0.32 \pm 0.11$ and $0.95 \pm 0.35 \mu \mathrm{m}$ respectively (figure 7).

The statistical comparison of the surface roughness values measured every time the experiment was stopped, returned p-values of 0.015, 0.012, 0.002, 0.012 and, 0.000 for contact stresses of 1.11, 1.38, 1.61, 2.00 and 5.30 MPa respectively. Thus, the surface roughness values of the all of the test pins changed significantly throughout the experiment. 
The surface roughness values of the discs before and after the test showed a significant difference (p-value: 0.006); however, after the bedding-in phase (the first 500,000 cycles), this difference became insignificant (Figure 8) (p-value: 0.99).

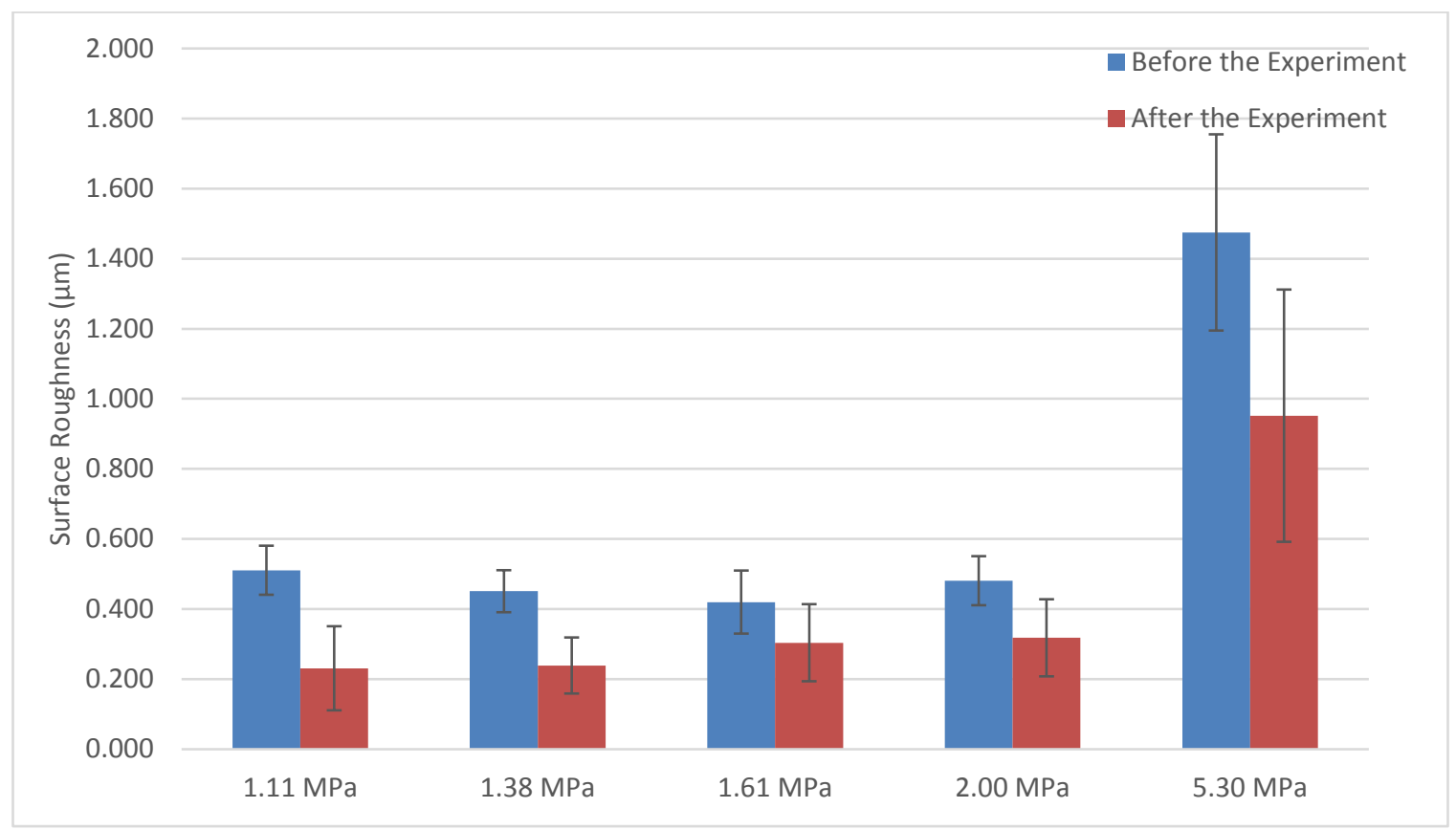

Figure 7. Surface roughness values of the test pins before and after the experiment.

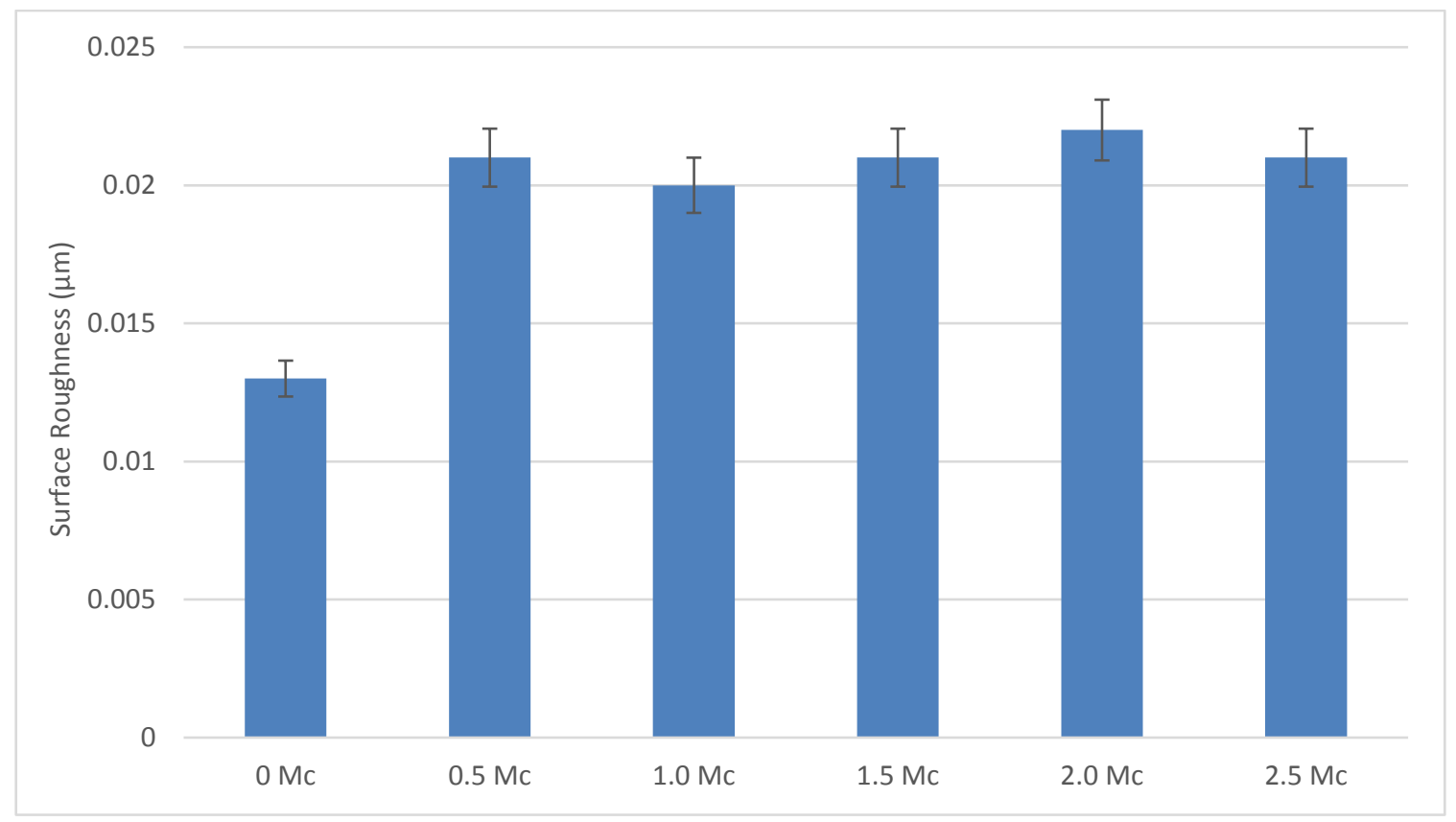

Figure 8. Surface roughness values of the CoCr discs. 


\section{Discussion}

This is the first time that the influence of contact stress on wear of XLPE has been reported in a high capacity study. The SuperCTPOD allowed wear testing of 50 pins under 5 different contact stresses. The results of the study showed that wear of XLPE decreased with increasing contact stress.

Apart from the area of contact, every experimental condition was kept constant. The wear rates of the XLPE pins were found to be similar to previous studies ${ }^{4,}{ }^{20}$. Group 1 (1.11 MPa, 10 XLPE test pins) was tested under the same experimental conditions as Harsha and

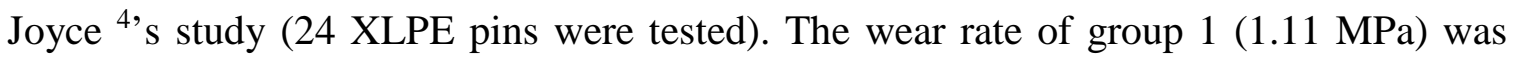
calculated to be $1.1 \pm 0.4 \mathrm{mg}$ per million cycles and Harsha and Joyce ${ }^{4}$ calculated a wear rate of $1.5 \pm 0.6 \mathrm{mg}$ per million cycles.

Unlike other studies that utilised UHMWPE pins for wear analysis ${ }^{4,25,26}$, the changes in the weight of the control pins were found to be significant for group 4 (2.00 MPa) and group 5 (5.30 MPa) (p value=0.00 for both of the groups) of this study. For other groups the control pins did not show a significant influence.

In our study we chose to create different contact stresses by using an annulus. The alternative would have been pins with a reduced outer diameter. We chose the former over the latter as we felt it resulted in a more rigid wear face and it seemed a more straightforward and consistent method of manufacture.

Effect of contact stress on wear of XLPE

At the end of the experiment, a decreasing trend of the volume loss for an increasing contact stress was found for the test pins. Group $1(1.11 \mathrm{MPa})$ had the smallest contact stress and the highest mean volume loss $\left(2.81 \mathrm{~mm}^{3}\right)$ while group 5 (5.30 MPa) had the highest contact stress and the smallest mean volume loss $\left(0.75 \mathrm{~mm}^{3}\right)$ (figure 5$)$. It has been suggested that a reason for this phenomenon is because more asperities are in contact in surfaces with larger contact areas. For a given material, even at low loads, the larger contact areas result in higher wear rates ${ }^{33}$.

Some in-vitro studies described the wear behaviour of UHMWPE by giving the relation between wear factor and contact stress ${ }^{8,24-26}$. For comparison, the wear factors for each XLPE group (contact stresses ranging from 1.11 to $5.30 \mathrm{MPa}$ ), given in table 4, are 
represented with a power function, $k=0.40 * 10^{-6} * \sigma^{-0.88}$. This function (see figure 9) was found to be similar to the relationships found by Vassiliou and Unsworth ${ }^{24}$ and Saikko ${ }^{25,26}$, given in table 1.

Effect of contact stress on the wear of UHMWPE compared to XLPE In-vitro studies conducted by Saikko ${ }^{25,}{ }^{26}$, Vassiliou and Unsworth ${ }^{24}$, Barbour et al. ${ }^{8}$ and Wang et al. ${ }^{27}$ showed that at higher contact stresses, the wear of UHMWPE was lower compared to lower contact stresses. In this study, it was shown that wear from the XLPE pins was also lower at higher contact stresses.

As shown in figure 9, the wear behaviour of all of the pins were found to be similar to that reported by Vassiliou and Unsworth ${ }^{24}$. The change in wear factor was linear for contact stresses ranging from 1.11 to $1.61 \mathrm{MPa}$ and in between 1.61 to $2.00 \mathrm{MPa}$ a gradual decrease was observed in both of the studies. However, a steeper decline was observed in wear factor as the contact stress was varied from 2.00 MPa to 5.30 MPa for UHMWPE, than for XLPE.

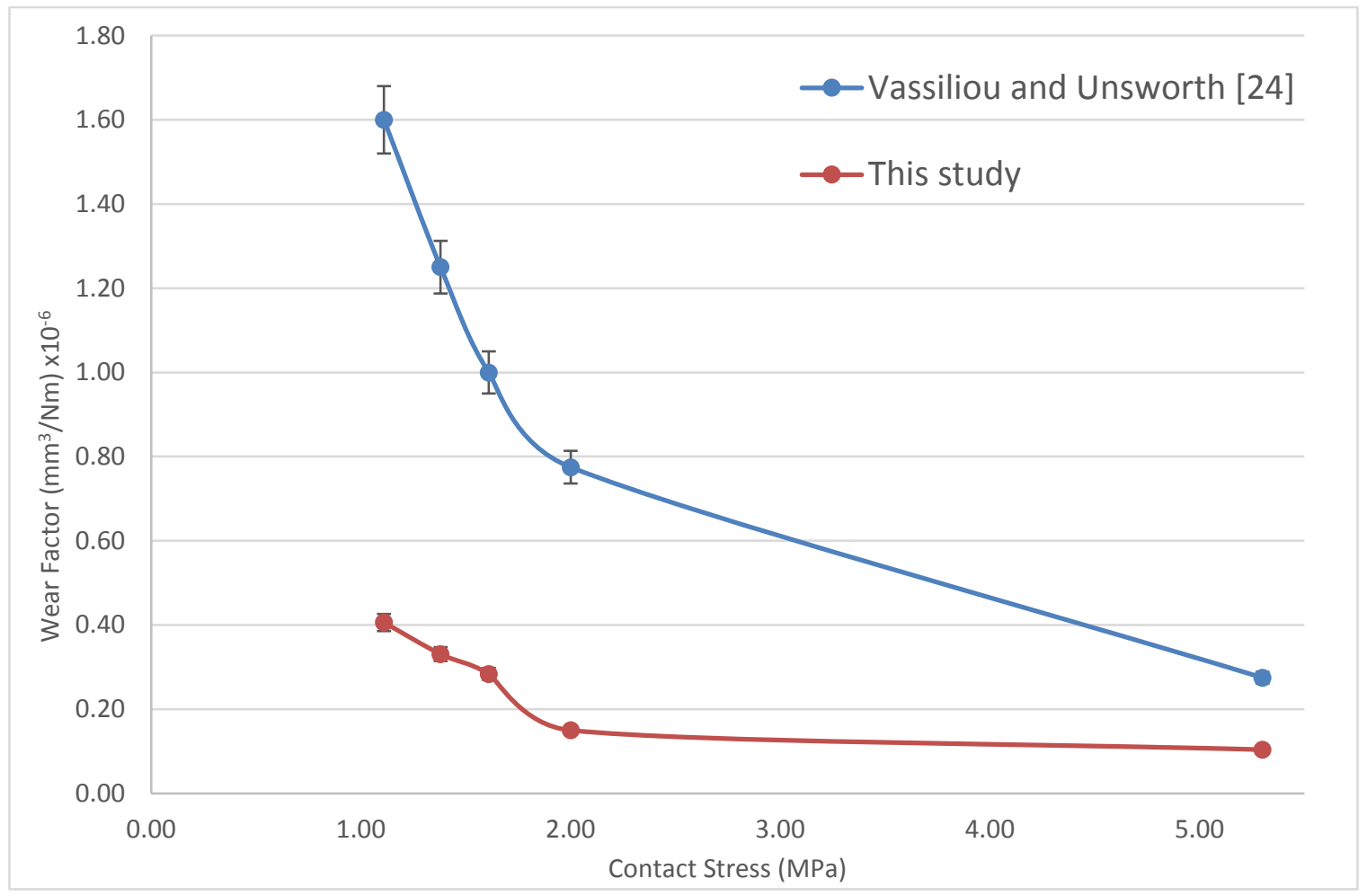

Figure 9. Comparison of the wear factor of UHMWPE and XLPE at contact pressures 1.11, 1.38, 1.61, 2.00 and 5.30 MPa respectively. The UHMWPE wear factor results were obtained from Vassiliou and Unsworth ${ }^{24}$. 
The wear equation

According to equation (1), the wear factor changes when the applied load and/or the sliding distance changes. However, that equation does not provide any information about the effect of contact stress on the wear factor. Based on this study's findings, the contact stress influenced the wear behaviour of the XLPE pins. Hence, equation (1) alone is not enough to explain the wear behaviour of polyethylene. The contact pressure acting on the material should also be considered when considering wear.

Surface roughness of the XLPE test pins and discs

As in similar studies, the test pin surface roughness values ( $\mathrm{Ra}$ ) decreased significantly with respect to their initial values ${ }^{4,25}$. In Harsha and Joyce ${ }^{4}$ 's study the surface roughness of the unworn XLPE test pins were $0.79 \mu \mathrm{m}$ and it reduced to $0.076 \pm 0.028 \mu \mathrm{m}$ Ra at the end of the experiment. Saikko ${ }^{25}$ also mentioned that after the test, the contact surface of the test pins were significantly burnished. Nevertheless, as demonstrated in figure 7, in this study the amount of decrease was not the same among the five XLPE groups. The group of pins having the highest contact stress (group $5-5.30 \mathrm{MPa}$ ) had the roughest surfaces at the end of testing and the pins from the group having the lowest contact stress (group 1-1.11 MPa) had the smoothest surfaces. The difference between the measured surface roughness values for the other groups was in between and the final surface roughness values showed an increasing trend with respect to an increase in contact stress. The relatively higher surface roughness values of group 5 (5.30 $\mathrm{MPa})$ pins can be attributed to the changes in the surface topography of the pins, i.e. protuberance formation. In Saikko 25, s study, protuberances were also observed on the pin surfaces at contact stresses higher than 2.00 MPa. As they were not observed in-vivo therefore, were considered to be clinically invalid ${ }^{25}$.

There was an increase in the surface roughness values of the discs after the first 500,000 cycles (running-in) from 0.013 to $0.021 \mu \mathrm{m}$ Ra (figure 8). However, after the running in period, there was no significant change in the surface roughness values $(p=0.006)$. The initial surface roughness values of the CoCr discs were in the range of 0.008 to $0.015 \mu \mathrm{m}$ Ra (average: $0.013 \mu \mathrm{m}$ ) and the final surface roughness of the discs were in the range of 0.009 to $0.036 \mu \mathrm{m}$ Ra (average: $0.021 \mu \mathrm{m}$ ). In the Vassiliou and Unsworth ${ }^{24}$ study, the initial surface roughness values measured for their stainless steel plates were in the range 
of 0.005 to $0.013 \mu \mathrm{m}$ Ra and the final surface roughness was in the range of 0.008 to 0.090 $\mu \mathrm{m}, \mathrm{Ra}$.

The surface roughness values of the discs did not show a significant difference as the contact stress changed. A p-value of 0.4 was calculated when the discs used for each group was compared at the end of the experiment, which is higher than the significance level.

This study has some limitations. First, wear debris from the test pins was not analysed. However, the main aim of this study was to observe the influence of contact stress on the wear of XLPE. Wear debris analysis will be the topic of a future study. Second, the maximum contact stress investigated was $5.30 \mathrm{MPa}$, even though the peak contact stresses can be higher in the natural hip joint. However, we were guided by previous work which suggested that non-clinically relevant findings were observed above $2 \mathrm{MPa}^{26}$. Indeed, as shown in figure 5, we too found that a similar situation applied. We would also note that we have undertaken wear tests at contact stresses relevant to the hip, these stresses are different to those in joint such as the knee and this may be a useful area for future research; although hopefully our results offer a useful starting point.

\section{Conclusion}

This study is the first to investigate the effect of contact stress on the wear behaviour of XLPE. Five groups of XLPE pins having different contact areas were tested under identical conditions at clinically relevant contact stresses. The results showed that the wear factor of the XLPE pins decreased with increasing contact stress. This finding was consistent with the studies on UHMWPE in the literature.

\section{Acknowledgements}

The experiment was carried out in the School of Engineering at Newcastle University.

\section{Funding}

The authors received no financial support for the research, authorship, and/or publication of this article. 


\section{References}

1. Di Puccio F and Mattei L. Biotribology of artificial hip joints. World journal of orthopedics 2015; 6: 77. DOI: $10.5312 /$ wjo.v6.i1.77.

2. Learmonth ID, Young $C$ and Rorabeck $C$. The operation of the century: total hip replacement. Lancet 2007; 370: 1508-1519.

3. Abdelgaied A, Brockett CL, Liu F, et al. Quantification of the effect of cross-shear and applied nominal contact pressure on the wear of moderately cross-linked polyethylene. Proceedings of the Institution of Mechanical Engineers, Part H: Journal of Engineering in Medicine 2013; 227: 18-26. DOI: 10.1177/0954411912459423.

4. Harsha AP and Joyce T. Comparative wear tests of ultra-high molecular weight polyethylene and cross-linked polyethylene. Proceedings of the Institution of Mechanical Engineers, Part H: Journal of Engineering in Medicine 2013; 227: 600-608.

5. NHS. Hip Replacement, https://www.nhs.uk/conditions/hip-replacement/ (2016, accessed 4/11/2017).

6. $\quad$ NJR. National Joint Registry 14th Annual Report 2017. 2017.

7. Endo M, Tipper JL, Barton DC, et al. Comparison of wear, wear debris and functional biological activity of moderately crosslinked and non-crosslinked polyethylenes in hip prostheses. Proceedings of the Institution of Mechanical Engineers, Part H: Journal of Engineering in Medicine 2002; 216: 111-122. DOI: 10.1243/0954411021536333.

8. Barbour PSM, Barton DC and Fisher J. The influence of contact stress on the wear of UHMWPE for total replacement hip prostheses. Wear 1995; 181: 250-257. DOI: 10.1016/0043-1648(95)90031-4.

9. Mu Z, Tian J, Wu T, et al. A systematic review of radiological outcomes of highly cross-linked polyethylene versus conventional polyethylene in total hip arthroplasty. International Orthopaedics 2009; 33: 599-604. DOI: 10.1007/s00264-008-0716-7.

10. Kurtz S, Gawel H and Patel J. History and Systematic Review of Wear and Osteolysis Outcomes for First-generation Highly Crosslinked Polyethylene. Clinical Orthopaedics and Related Research ${ }^{\circledR} 2011 ; 469$ : 2262-2277. DOI: 10.1007/s11999-011-1872-4.

11. Glyn-Jones S, Isaac S, Hauptfleisch J, et al. Does Highly Cross-Linked Polyethylene Wear Less Than Conventional Polyethylene in Total Hip Arthroplasty? The Journal of Arthroplasty 2008; 23: 337-343.

12. Abu-Amer Y, Darwech I and Clohisy J. Aseptic loosening of total joint replacements: mechanisms underlying osteolysis and potential therapies. Arthritis Res Ther. 2007.

13. Baxter RM, Macdonald DW, Kurtz SM, et al. Characteristics of highly cross-linked polyethylene wear debris in vivo. Journal of Biomedical Materials Research Part B: Applied Biomaterials 2013; 101: 467475. DOI: 10.1002/jbm.b.32902.

14. Kuzyk PRT, Saccone M, Sprague S, et al. Cross-linked versus conventional polyethylene for total hip replacement: A META-ANALYSIS OF RANDOMISED CONTROLLED TRIALS. The Bone \&amp; Joint Journal 2011; 93-B: 593-600. DOI: 10.1302/0301-620X.93B5.25908.

15. Campbell D, Field J and Callary S. Second-generation Highly Cross-linked X3 ${ }^{\text {тм }}$ Polyethylene Wear: A Preliminary Radiostereometric Analysis Study. Clinical Orthopaedics and Related Research ${ }^{\circledR} 2010 ; 468$ : 2704-2709. DOI: 10.1007/s11999-010-1259-y.

16. Olyslaegers C, Defoort K, Simon J-P, et al. Wear in Conventional and Highly Cross-Linked Polyethylene Cups: A 5-Year Follow-Up Study. The Journal of Arthroplasty 2008; 23: 489-494. DOI: 10.1016/j.arth.2007.02.013.

17. Reynolds SE, Malkani AL, Ramakrishnan R, et al. Wear Analysis of First-Generation Highly CrossLinked Polyethylene in Primary Total Hip Arthroplasty:An Average 9-Year Follow-Up: An Average 9-Year Follow-Up. The Journal of Arthroplasty 2012; 27: 1064-1068. DOI: 10.1016/j.arth.2012.01.006.

18. Gaudiani MA, Ranawat AS and Ranawat CS. Wear Analysis of Highly Cross-Linked Polyethylene in Young and Active Patients at Average Fourteen Years: A Concise Follow-Up of a Previous Report. The Journal of Arthroplasty 2018; 33: 586-589. DOI: 10.1016/j.arth.2017.09.007. 
19. Bookman JS, Kaye ID, Chen KK, et al. 10-Year Follow-Up Wear Analysis of Marathon Highly CrossLinked Polyethylene in Primary Total Hip Arthroplasty. The Journal of Arthroplasty 2017; 32: 2587-2589. DOI: 10.1016/j.arth.2017.03.016.

20. Affatato S, Bersaglia G, Rocchi M, et al. Wear behaviour of cross-linked polyethylene assessed in vitro under severe conditions. Biomaterials 2005; 26: 3259-3267. DOI:

10.1016/j.biomaterials.2004.07.070.

21. Joyce T. CORR Insights ${ }^{\circledR}$ : The John Charnley Award: Highly Crosslinked Polyethylene in Total Hip Arthroplasty Decreases Long-term Wear: A Double-blind Randomized Trial. Clinical Orthopaedics and Related Research ${ }^{\circledR}$ 2015; 473: 439-440. DOI: 10.1007/s11999-014-3906-1.

22. Brand RA. Joint contact stress: a reasonable surrogate for biological processes? The lowa orthopaedic journal 2005; 25: 82-94.

23. Henak C, Kapron A, Anderson A, et al. Specimen-specific predictions of contact stress under physiological loading in the human hip: validation and sensitivity studies. Biomechanics and Modeling in Mechanobiology 2014; 13: 387-400. DOI: 10.1007/s10237-013-0504-1.

24. Vassiliou $\mathrm{K}$ and Unsworth $\mathrm{A}$. Is the wear factor in total joint replacements dependent on the nominal contact stress in ultra-high molecular weight polyethylene contacts? Proceedings of the Institution of Mechanical Engineers, Part H: Journal of Engineering in Medicine 2004; 218: 101-107. 25. Saikko V. Effect of contact area on the wear of ultrahigh molecular weight polyethylene in noncyclic pin-on-disk tests. Tribology International 2017; 114: 84-87.

26. Saikko V. Effect of contact pressure on wear and friction of ultra-high molecular weight polyethylene in multidirectional sliding. Proceedings of the Institution of Mechanical Engineers, Part H: Journal of Engineering in Medicine 2006; 220: 723-731.

27. Wang A, Essner A and Klein R. Effect of contact stress on friction and wear of ultra-high molecular weight polyethylene in total hip replacement. Proceedings of the Institution of Mechanical Engineers, Part H: Journal of Engineering in Medicine 2001; 215: 133-139. DOI: 10.1243/0954411011533698.

28. Bragdon CR, Connor DO, Lowenstein JD, et al. The Importance of Multidirectional Motion on the Wear of Polyethylene. Proceedings of the Institution of Mechanical Engineers, Part H: Journal of Engineering in Medicine 1996; 210: 157-165. DOI: 10.1243/PIME_PROC_1996_210_408_02.

29. Saikko V. A Hip Wear Simulator with 100 Test Stations. Proceedings of the Institution of Mechanical Engineers, Part H: Journal of Engineering in Medicine 2005; 219: 309-318. DOI: 10.1243/095441105X34301.

30. Jones SR, Carley S and Harrison M. An introduction to power and sample size estimation. Emergency Medicine Journal 2003; 20: 453. DOI: 10.1136/emj.20.5.453.

31. Saikko V. Effect of lubricant protein concentration on the wear of ultra-high molecular weight polyethylene sliding against a CoCr counterface. Journal of Tribology 2003; 125: 638-642. DOI: 10.1115/1.1537751.

32. Joyce TJ, Grigg H, Langton DJ, et al. Quantification of self-polishing in vivo from explanted metalon-metal total hip replacements. Tribology International 2011; 44: 513-516. DOI:

10.1016/j.triboint.2010.04.007.

33. Bhushan B. Introduction to tribology. New York: New York : John Wiley, 2002. 